\title{
Diabetes mellitus tipo 2 con mal control metabólico, ¿un caso más?
}

\begin{abstract}
María Julia Hernández-Vidal' ${ }^{1}$ Mariana Martínez-Martínez ${ }^{2}$, Raquel Meseguer-Noguera' ${ }^{1}$
'Servicio de Medicina Interna. Hospital General Universitario Rafael Méndez. Lorca (Región de Murcia). España

${ }^{2}$ Servicio de Endocrinología. Hospital Comarcal del Noroeste. Caravaca de la Cruz (Región de Murcia). España
\end{abstract}

Recibido: 16/11/2018

Aceptado: 01/01/2019

En línea: 31/01/2019

Citar como: Hernández-Vidal MJ, Martínez-Martínez M, Meseguer-Noguera R. Diabetes mellitus tipo 2 con mal control metabólico, ¿un caso más? Rev Esp Casos Clin Med Intern (RECCMI). 2019 (Ene); 4(Supl 1): 19-21. doi: 10.32818/reccmi.a4s1a8.

Autor para correspondencia: María Julia Hernández-Vidal. majirulihv@gmail.com

\section{Palabras clave \\ $\triangleright$ Diabetes \\ $\triangleright$ Herencia monogénica \\ $\triangleright$ MODY tipo 3}

\begin{abstract}
Resumen
Presentamos el caso de una paciente con diagnóstico de diabetes tipo MODY catalogada inicialmente como diabetes mellitus tipo 2. Ciertos datos, como antecedentes familiares, diagnóstico en la vida adulta temprana, ausencia de obesidad y rápida evolución hacia tratamiento insulínico, nos hizo plantear la posibilidad de que el diagnóstico inicial de DM2 fuera erróneo, por lo que se solicitó análisis genético-molecular que constató la existencia de una mutación del gen del factor nuclear 1 alfa de hepatocito (HNF-1a) que concuerda con una diabetes monogénica tipo 3.

Abstract
We are presenting a patient with MODY type diabetes that had previously been catalogue as type 2 diabetes me-
llitus. Family history, absence of obesity, been diagnosed in early adult life and the fast evolution from antidiabetic
drugs towards insulin treatment made us consider that our initial diagnosis was erroneous, and for that reason a
genetic-molecular analysis was requested. Finally, the existence of a mutation of the hepatocyte nuclear factor 1
alpha gene (HNF-1a) that agrees with a type 3 monogenic diabetes was confirmed.
\end{abstract}

\section{Puntos destacados}

$\triangleright$ Deberemos sospechar la existencia de una diabetes asociada a defectos y mutaciones en los factores de transcripción en aquellos pacientes que no encajan dentro de las formas más comunes de diabetes, con diagnóstico antes de los 25 años y con antecedentes familiares con fenotipos similares.

\section{Introducción}

La diabetes mellitus (DM) engloba un grupo de trastornos variado. Las formas más prevalentes, tipo 1 y 2, están causadas por una alteración poligénica, pero se conocen otros tipos de diabetes que se deben a la mutación de un solo gen (monogénicas) ${ }^{1}$. En este último grupo, la fisiopatología de la enfermedad puede justificarse por una deficiencia de insulina, entre ellas la diabetes tipo MODY (siglas del inglés madurity onset diabetes of the young), o por una grave resistencia a la insulina.

En muchas ocasiones, la diabetes tipo MODY es inicialmente mal diagnosticada, considerándose como DM tipo 1 o 2. Existen algunos datos que deben hacernos sospechar esta entidad; y en esos casos, hay que confirmar su existencia mediante el estudio genético².
Presentamos el caso de una mujer de 48 años derivada a consulta para seguimiento y control de diabetes mellitus por irregular control metabólico.

\section{Historia clínica: antecedentes, enfermedad actual y exploración física}

- Antecedentes personales. Mujer de 48 años sin alergias medicamentosas conocidas, diagnosticada de DM a los 24 años de edad, actualmente con retinopatía diabética no proliferativa. Entre sus antecedentes destacaba además un hábito tabáquico activo (10 cigarrillos/día desde los 17 años) y cardiopatía isquémica revascularizada (infarto agudo de miocardio a los 43 años). No tenía otros factores de riesgo cardiovascular conocidos ni enfermedades medicoquirúrgicas de interés. Como tratamiento actual tomaba un comprimido cada 12 horas de metformina y se administraba 18 unidades (UI) en la comida de mezcla fija de insulina aspart/insulina aspart protamina 70/30 y 10 UI en desayuno y cena de insulina aspart.

- Antecedentes familiares. Tenía una hija con DM diagnosticada con 18 años inicialmente tratada con insulina y actualmente con antidiabéticos orales 
con buen control metabólico, madre con diabetes en tratamiento con fármacos orales y abuela materna con DM en tratamiento insulínico. Hermanos sanos.

- Enfermedad actual. Paciente derivada a consulta de nuestro centro para seguimiento y control de su diabetes. Revisando historia clínica comprobamos que la mujer fue diagnosticada a la edad de 24 años de una diabetes catalogada hasta el momento como tipo 2. Inicialmente fue tratada con antidiabéticos orales (aproximadamente durante 10 años) y posteriormente insulinizada. Seguida hasta el momento en otro centro en consulta de Endocrinología con mal control glucémico. Nunca ha presentado descompensaciones cetósicas. No tiene sobrepeso ni obesidad. Está en tratamiento con una dosis de mezcla fija de insulina al día y dos dosis de análogo ultrarrápido, junto con metformina. Se realiza tres autocontroles al día presentando glucemia basal habitual $>200 \mathrm{mg} / \mathrm{dl}$ y preprandiales en torno a 230-240 mg/dl. No aporta controles posprandiales. Niega hipoglucemias.

- Exploración física. Talla 1,63 m; peso 64,9kg, índice de masa corporal 24. Tensión arterial 125/65 mmHg. Buen estado general. Sin alteraciones en exploración básica (auscultación cardiopulmonar y abdominal normales), miembros inferiores con pulsos pedios palpables y simétricos, sin alteraciones de la sensibilidad táctil, propioceptiva ni vibratoria.

\section{Pruebas complementarias}

Analítica incluyendo función renal, hepática, iones, perfil lipídico, TSH y hemograma normales. Hemoglobina glicosilada 9,7\%.

\section{Evolución}

Debido al mal control glucémico que presenta con la pauta insulínica actual, decidimos modificarla al siguiente esquema:

- Insulina glargina: 30 UI vía subcutánea una vez al día.

- Insulina aspart: 10-12-10 UI vía subcutánea en desayuno, comida y cena, respectivamente.

Por otro lado, aunque la diabetes que presentaba la paciente había sido catalogada como tipo 2, los antecedentes familiares y la propia evolución de la enfermedad con diagnóstico en la vida adulta temprana, ausencia de obesidad y rápida evolución hacia tratamiento insulínico, nos hizo plantear otros tipos distintos de diabetes. Inicialmente solicitamos autoinmunidad pancreática que resultó negativa, y péptido $\mathrm{C}$ con resultado de $0,56 \mathrm{ng} / \mathrm{ml}$ (rango normalidad de laboratorio: 0,26-1,44). Ante estos resultados, decidimos proseguir con el estudio y solicitamos el análisis genético-molecular, que concluyó la existencia de una mutación del gen del factor nuclear 1 alfa de hepatocito (HNF-1a).

\section{Diagnóstico}

Diabetes monogénica MODY 3.

\section{Discusión y conclusiones}

La diabetes comprende un grupo heterogéneo de trastornos que varían en cuanto a etiología, manifestaciones clínicas y modo de herencia. Las formas más prevalentes de DM son la tipo 1 y la tipo 2, causadas por alteración de varios genes (poligénicas), pero existen otros tipos de diabetes cuyo origen radica en la mutación de un gen (monogénicas). En estas últimas podemos distinguir dos grupos según su forma de presentación:

- Formas en las que predomina la deficiencia de insulina:

- Diabetes tipo MODY.

- Diabetes neonatal transitoria y permanente.

- Diabetes mitocondrial.

- Formas en las que predomina la resistencia grave a la insulina:

- Diabetes debida a mutaciones del gen del receptor de la insulina.

- Diabetes congénita lipoatrófica.

La diabetes tipo MODY representa el 1-5\% de todos los tipos de diabetes. Se debe a defectos genéticos que afectan a la formación y función de la célula beta. Se caracteriza por ser una diabetes familiar, ya que tiene una herencia autosómica dominante (mutaciones en estado heterocigoto) con alta penetrancia y expresión precoz (habitualmente antes de los 25 años). Es genéticamente heterogénea, ya que se han descrito varias mutaciones (actualmente se conocen siete subtipos distintos) ${ }^{3}$. Las diferencias de los distintos tipos de MODY se encuentran, sobre todo, en la edad de inicio, el patrón de hiperglucemia y la respuesta al tratamiento.

La DM tipo MODY es en muchas ocasiones incorrectamente diagnosticada como DM tipo 1 o 2. Los datos que nos deben hacer sospechar esta entidad son:

- Aparición de $\mathrm{DM}<6$ meses de vida.

- Clara herencia familiar.

- DM1 con autoanticuerpos negativos

- Persistencia de péptido C a los 3 años del diagnóstico.

- DM2 sin obesidad y sin evidencia de resistencia a la insulina.

- Hiperglucemia media en ayunas estable y persistente en un sujeto joven o con historia familiar positiva.

El diagnóstico se confirmará mediante el estudio molecular para la búsqueda de las mutaciones. Tres genes son los responsables de la mayoría de casos: GCK, HNF-1a y HNF-4 a. El caso que presentamos es una diabetes MODY 3. Se debe a la mutación del gen HNF-1a y es la forma más frecuente de MODY en la población adulta. El gen HNF-1a se encuentra en el cromosoma 12q y regula la expresión de otros genes necesarios para la función de las células beta, siendo esencial para la transcripción del gen de la insulina. Su mutación cursa con un defecto progresivo de la célula beta que a la larga conlleva una marcada hiperglucemia (sobre todo posprandial) con complicaciones microvasculares asociadas. Generalmente se desarrolla después de la pubertad o en la edad adulta precoz y con frecuencia suele presentar síntomas osmóticos (sin cetosis) debido a la disminución del umbral renal para la glucosa. La obesidad no es común. Requieren tratamiento en la mayoría de los casos. Inicialmente, responden muy bien a sulfonilureas y con la progresión de la enfermedad suelen requerir insulinoterapia.

En conclusión, el diagnóstico de DM1 con autoanticuerpos negativos o de DM2 sin obesidad y sin evidencia de resistencia a la insulina y/o la persistencia de péptido $C$ a los 3 años del diagnóstico, son algunos supuestos que deben hacernos considerar un diagnóstico alternativo, estando indicada la solicitud de estudio genético.

\section{Bibliografía}

1. Mc Culloch DK. Classification of diabetes mellitus and genetic diabetic syndromes. UpToDate. 2015.

2. Barrio R. Diabetes monogénicas: enfoque diagnóstico y tipos más frecuentes. Av Diabetol. 2007; 23(5): 333-340. 
3. Polo-Soto SM, González-Díaz CA, González-Rui N, Altamirano-Díaz I, Lucio-Monter PF, Martínez-Salas SG, et al. MODY: formas monogénicas de diabetes. Rev Sanid Milit Mex. 2009; 63(5) Sep-Oct: 250-254.
4. Global IDF/ISPAD guideline for diabetes in childhood and adolescence. International Diabetes Federation. 2011. 